\title{
Comparison between Immediate Effect of Neural Mobilization and Myofascial Release of Suboccipital Muscle on Hamstring Length in Younger Adults - An Interventional Study
}

\author{
HS Krishna ${ }^{*}$, Sreejisha PK ${ }^{* *}$, Chetan Dhote ${ }^{* * *}$ \\ *Professor, ${ }^{* *}$ Assistant Professor, ${ }^{* * *}$ Post Graduate Student, Laxmi Memorial College of Physiotherapy, \\ Rajiv Gandhi University of Health Sciences, Karnataka, India \\ Corresponding Author: Chetan Dhote
}

\begin{abstract}
Background and objectives: Shortening of hamstring has a negative impact on the posture of the pelvic region. The increase in stiffness of the hamstring may serve as a cause of low back pain and is also thought to predispose athletes to injury. The objective of this study was to compare the immediate effect of neural mobilization and myofascial release of suboccipital muscle on hamstring length in younger adults.

Methodology: This was a Comparative study conducted in a tertiary care hospital. A total 40 individuals between age group of 18-25 years having reduced hamstring length were included in this study. They were randomly divided into two groups by lottery method. Group 1 received neural mobilization and group 2 received myofascial release of suboccipital muscle. Ranges were recorded post treatment. Straight Leg Raise (SLR), Sit and Reach Test (SR) and Finger to Foot Test (FFT) were used to record pre treatment ranges

Results: The result revealed that hamstring length significantly improved in both the groups further between the groups comparison demonstrated that non-significant difference existed in improvement scores of SLR, where as statistically not significant but clinically significant difference was existed in improvement of FFT. Furthermore between groups comparison demonstrated that statically and clinically significant difference existed in improvement scores of sit and reach, indicating that neural mobilization was more effective in
\end{abstract}

improving hamstring length then myofascial release of suboccipital muscle in improving hamstring length.

Conclusion: This study concluded that both neural mobilization and myofascial release of suboccipital muscle is effective in increasing length of hamstring muscle, where as neural mobilization was better when assessed with sit and reach test.

Keywords: Hamstring length, neural mobilization, myofascial release, suboccipital muscle, sit and reach test, Straight leg raise, finger to foot test.

\section{INTRODUCTION}

Flexibility is the ability to move a single joint or a series of joints smoothly and easily through an unrestricted, pain free range of motion. Whereas inability of a muscle or muscle group to move through a full range of motion for a specified body part is known as muscle tightness.

On the surface muscle tightness may appear to be a simple aliment; however, there are squeal to muscle tightness that intensify if not treated immediately and appropriately. It is not uncommon for untreated calf and hamstring muscle tightness to lead to plantar fasciitis, a painful foot condition that can adversely affect gait. Therefore muscle tightness requires immediate attention to prevent it 
HS Krishna et.al. Comparison between immediate effect of neural mobilization and myofascial release of suboccipital muscle on hamstring length in younger adults-an interventional study

from becoming a chronic condition and to prevent further complications.

Hamstrings are a group of muscles and their tendons at the rear of the upper leg. They include the Biceps femoris, Semitendinosus and Semimembranosus. ${ }^{1} \mathrm{~A}$ portion of the adductor magnus is sometime considered a part of hamstring ${ }^{2}$. Hamstrings contribute to posture stabilization and the control of the pelvis region.

Shortening of hamstring has a negative impact on the posture of the pelvic region. The increase in stiffness of the hamstring may serve as a cause of low back pain $(\mathrm{LBP})^{3,4}$ A lack of hamstring extensibility is thought to induce changes in lumbopelvic rhythm. Reduced hamstring extensibility is also thought to predispose athletes to injury.

Shortening of the hamstring can be examined by the finger-foot distance (FFD), straight leg test (SLR) and sit and reach test (SR). If a person cannot touch the floor with fingertips in the bent-forward position or the SLR is lower than $80^{\circ}$, the person is considered to have short hamstring extensibility. ${ }^{5}$

Too much sitting, overuse, weakness, injury, pelvic problems are some of the common causes of hamstring tightness. Physiological causes of reduced muscle extensibility relate to the contractility of the muscle cell.

Increases in tissue flexibility may result, not from affecting the mechanical properties of the muscle being stretched, but from changes in the individual's perception of stretch or pain. The point of limitation in hamstring range may increase, not because of changes within the muscle structure itself but rather because the individual experiencing the stretching may adopt a new stop point for limitation in hamstring range based on altered perceptions of stretch and pain. ${ }^{6,7}$ Increases in muscle flexibility after stretching were likely due to the modified sensation. Nerve adhesions within the hamstring may alter neurodynamics causing abnormal mechanosenitivity of the sciatic nerve; which could influence hamstring flexibility. This mechanosensitivity of the neural tissue could limit hamstring length in normal healthy individuals ${ }^{8,9}$. Protective muscle contraction of the hamstring muscle found in the presence of the neural mechanosenisitivity may occur for hamstring tightness and thereby predisposing the muscle to subsequent strain injury ${ }^{6,10}$

Providing movement or stretching could lead to changes in the neurodynamics and modification of sensation and could help in increase flexibility. ${ }^{11-16}$

Another technique which can be effective for hamstring tightness is myofascial release of suboccipital muscle. Myofascial release is an alternative medicine therapy claimed to be useful for treating skeletal muscle immobility and pain by relaxing contracted muscles, improving blood Oxygen and lymphatic circulation and stimulating the stretch reflex in muscle Myofascial release of suboccipital muscle is widely used in manual therapy. Its importance to the upper cervical spine is well-known among professionals involved in manual therapy, but its relationships with other distant structures have not yet been identified. Schleip, considers that if the tone of the suboccipital muscles is decreased (passively, with a fascial treatment, or with active movements), the length of the hamstring muscles increases and the increase in the amplitude of hip flexion will be greater. ${ }^{17}$ The continuity of the neural system links the dura matter inserted into the suboccipital muscles and the hamstring muscles. An obstruction to the movement of the dura mater at these sites may affect the degree of movement allowed by the lower limb owing to the tensions of the peripheral roots of the nerve in the SLR test.

If there any tensions arise in the myofascial chain, it will result to hamstring tightness as both hamstring and suboccipital muscles belong to the posterior myofascial chain. The interest of the study is to find out whether myofascial release of Sub-occipital Muscles has any effects on hamstring length as there is scarce research 
regarding this technique and to find out the effectiveness of Neural mobilization and its effectiveness on hamstring length in young adults. The aim of this study is to compare the immediate effects of neural mobilization in lower limb and myofascial release of Sub-occipital Muscle on hamstring length in younger adults using different parameters.

\section{METHODOLOGY \\ Design and setting}

This was a comparative study conducted in a tertiary care hospital. It was approved by the Institutional Ethical Committee.

\section{Participants}

Participants between age group of 18-25 years having an SLR range of less than $80^{\circ}$, not able to touch the floor in standing and those who weren't able to touch their toes in long sitting were included in the study. Participants those had a history of hamstring injury within the past year, those exceeding $80^{\circ}$ of SLR, any history of neck trauma or any neck symptoms, any history of neurological or orthopedic disorders, those diagnosed with herniated disk, low back pain in last six months were excluded from the study.

\section{Procedure}

A brief introduction about the procedure was explained to all the participants. Those included on the basis of the inclusion and exclusion criteria were randomly allocated into two groups by lottery method. Then an initial examination including demographic data such as name, age, and gender were recorded. Participants were assessed using Straight leg raise test, Sit and reach test and finger to foot test and their scores were recorded. Those in group 1 received neural mobilization of lower limb for both the hamstrings. The participant was in supine position with their neck and thoracic spine supported in a forward flexed position. The therapist then carries out concurrent hip flexion, knee flexion and ankle dorsiflexion and alternated dynamically with concurrent hip extension, knee extension and ankle plantar flexion. The therapist alternates the combination of movement depending on the tissue resistance level. The technique was given passively and was performed for $180 \mathrm{sec}$ or 3 minutes (approximately 25th repetition). Post scores were recorded using outcome measures.

Subject in group 2 received myofascial release of Sub-occipital muscle. The subject was in supine lying with eyes close, therapist sat behind the subject's head with his elbow resting on the surface of the bed and places both the palm of his hand beneath the head of the subject; with the palm facing upwards, the finger flexed and the finger pads position on the posterior arch of the atlas. A force was applied on the atlas in the direction of the ceiling with slight traction in a cranial direction. The pressure was maintained for 2 minutes until tissue relaxation was achieved. Post innervations were assessed using straight leg raise test, sit and reach test and finger to foot

Test

\section{Outcome measures}

\section{$>$ Straight leg raise}

- The subjects were in supine, keeping the knee fully extended, the examiner flexes the subject's hip until reaching full flexion or until the subject experience discomfort and then the angle of hip was measured.

- The knee and ankle always remain in extension position.

- The passive SLR test recorded three times for each subjects using universal goniometer. $^{5}$

\section{$>$ Finger to floor}

- The subjects were asked to perform a maximum and progressive anterior flexion of the trunk, maintaining the knees in straight and lengthening the arms with the palms parallel and the finger extended.

- Metric tape was used to determine the distance from the distal part of the finger (middle finger) to the floor. ${ }^{5}$ 
HS Krishna et.al. Comparison between immediate effect of neural mobilization and myofascial release of suboccipital muscle on hamstring length in younger adults-an interventional study

\section{Sit and reach test}

- The starting position was sitting on the floor with shoes removed, feet flat against the table, and legs straight Reach forward and push the fingers along the table as far as possible.

- The distance from the finger tips to the edge of the table represents the score for that person.

- As the 'sit and reach' table has an overhang of $15 \mathrm{~cm}$, a person who reaches $10 \mathrm{~cm}$ past their toes scores 25 $\mathrm{cm}$.

- Several warm-up attempts were given first, and then the score was record.5

\section{Statistical analysis}

SPSS ver. 20 was used to analyses data. Descriptive statistic was sued for demographic data such as age, height, weight, gender. Paired t test was used to find the difference within group and unpaired t test was used to find between group differences.

\section{RESULT}

The demographic characteristics (mean age, height and weight) and baseline values of Straight leg raise (SLR); Finger to foot test (FFT); Sit and $\operatorname{reach}(\mathrm{SR})$ of the participants in both Neural mobilization (NM) and Myofascial release (MFR) groups showed non-significant differences indicating homogeneity of groups $(\mathrm{p}>0.05)$.

Within the group comparison, in Neural mobilization group significant differences was noted between baseline and post-intervention values of Straight leg raise

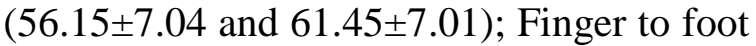
test $(14.80 \pm 4.11$ and $11.25 \pm 3.98)$; Sit and reach $(14.40 \pm 4.03$ and 10.65 \pm 4.06$)$ respectively. Similarly, in Myofascial release group significant differences was noted between baseline and postintervention values of Straight leg raise (53.90 \pm 7.06 and 58.75 \pm 6.90$)$; Finger to foot

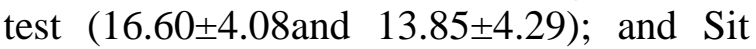
and reach test $(15.95 \pm 4.46$ and $13.85 \pm 4.93)$ $\mathrm{P}<0.001$.

Between group comparison, there was no significant difference was noted between the mean difference values of Neural mobilization and Myofascial release group-in Straight leg raise (5.30 and 4.85) and Finger to foot test (3.55 and 2.75) $(p>0.05)$. Whereas, significant difference was noted between the mean difference values of Neural mobilization and Myofascial release group-in Sit and reach test $(3.75$ and 2.10) $\mathrm{P}<0.001$. (Table1).

Table: 1

\begin{tabular}{|c|c|c|c|c|c|}
\hline \multicolumn{6}{|l|}{ SLR } \\
\hline & & Mean & SD & t value & p value \\
\hline $\mathrm{NM}$ & Pre - post & 5.30 & 1.38 & \multirow[t]{2}{*}{1.02} & \multirow{2}{*}{.310} \\
\hline MFR & Pre - post & 4.85 & 1.38 & & \\
\hline \multicolumn{6}{|l|}{ FFT } \\
\hline & & Mean & SD & t value & p value \\
\hline $\mathrm{NM}$ & Pre - post & 3.55 & 1.19 & \multirow[t]{2}{*}{1.46} & \multirow{2}{*}{.150} \\
\hline MFR & Pre - post & 2.75 & 2.12 & & \\
\hline \multicolumn{6}{|l|}{ SR } \\
\hline & & Mean & SD & t value & p value \\
\hline NM & Pre - post & 3.75 & 1.11 & \multirow[t]{2}{*}{3.25} & \multirow[t]{2}{*}{.002} \\
\hline MFR & Pre - post & 2.10 & 1.97 & & \\
\hline
\end{tabular}

Between group comparison of mean difference values (improvement scores) of ND group and MFR groups. 
HS Krishna et.al. Comparison between immediate effect of neural mobilization and myofascial release of suboccipital muscle on hamstring length in younger adults-an interventional study

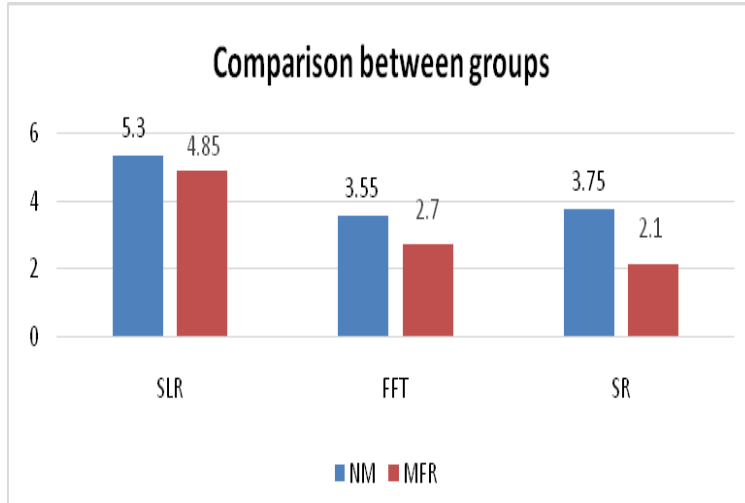

Graph 1: Graphical representation of comparison between group 1(NM) and 2 (MFR)

\section{DISCUSSION}

This study was carried out to compare the immediate effect of neural mobilization and myofascial release of suboccipital muscle. 40 participants fulfilling the inclusion criteria were selected. They were randomly divided into group 1 and group 2. Participants of group 1 received neural mobilization of lower limb and those in group 2 received myofascial release of suboccipital muscle for 2 minutes. Pre and post data was recorded using Straight Leg Raise (SLR), Finger to Foot Test (FFT) and Sit and reach test (SR).

The mean difference for neural mobilisation and Myofascial release of sub occipital muscle between the group was $(5.30,4.87)$ which was statistically not significant $(\mathrm{P}>0.05)$, when FFT values were compared, again statistically no significant difference was found but clinically group 1 showed better results than group 2 (mean difference group $1-3.55 \mathrm{~cm}$, mean difference group 2-2.75) and when sit and reach test values were compared, there was statistically significant difference was found $(\mathrm{P}<0.05)$ which was clinically significant too (mean difference group 1 is $3.75 \mathrm{~cm}$, group 2 is $2.1 \mathrm{~cm}$ ). Thus the values of sit and reach test of group 1 showed better results than group 2 .

Hence this study concluded that immediate effect of neural mobilization in lower limb is better than immediate effect of myofascial release of suboccipital muscle in increasing hamstring length. The work done by Castellote-caballero et $\mathrm{al}^{6}$ too had a similar result by concluding that neurodynamic sliding technique increases hamstring flexibility to a greater extent than static hamstring stretching in healthy subjects with short hamstring syndrome.

Till date many studies are done to increase hamstring flexibility which is focused on the varying modes of stretching such as proprioceptive neuromuscular facilitation $(\mathrm{PNF})^{18,19,}$ static stretching ${ }^{20}$, plyometric stretching and ballistic stretching $^{21}$. They have also compared the intensity $^{22}$ and frequencyes ${ }^{23}$ of different stretches.

Decrease in muscle length is also known as muscle tightness which can result in decrease range of motion. Various studies have been done which conclude that it is not only contractile tissue but non contractile tissues such as deep fascia, soft tissue surrounding the joint and even neurological tissues can limit the range of motion ${ }^{24,25}$.

Current evidences suggest altered posterior lower extremity neurodynamics (morphologic, physiological and integrated biomechanical function of nervous system) influences the resting muscle length and increase mechanosensitivity ${ }^{26,27}$, which then induces protective mechanism when stresses are imposed on them and result in decrease muscle extensibility. Neural mobilization includes manual therapy techniques (Gliding and stretching). It is used to treat adverse neural tension and is considered to improve neurodynamics, axoplasmic flow, maintaining dynamic balance between neural tissues and surrounding mechanical interfaces and thus decreases the mechanosensitivity ${ }^{28}$. T. Hall et al also concluded that neurodynamic sliding interventions can be thought to decrease neural mechenosensitivity and this was supported by other studies too. Furthermore, Jaemyoung Parka et $\mathrm{al}^{29}$ stated that when tension is applied to the nervous system while applying neurodynamics, it causes reduction in cross-sectional area and increase in pressure in the nerve that results in extension and movement of the sciatic nerve together with the hamstring and this 
HS Krishna et.al. Comparison between immediate effect of neural mobilization and myofascial release of suboccipital muscle on hamstring length in younger adults-an interventional study

compliance of the nerve, results in increased flexibility. When applying neurodynamics, tension that occurs in the nervous system and pressure within the nerve increases due to the decrease in cross-sectional area, and the axonal transport system lengthens the sciatic nerve after shortening because of the influence of the surrounding related structures and hamstring flexibility ${ }^{30}$.

In this study we also found that myofascial release of suboccipital muscle is also significantly effective in reducing hamstring tightness but less compared to neural mobilization. Effectiveness of myofascial release of suboccipital muscle is supported by Aparicio et $\mathrm{al}^{32}$ who conducted a study to check the immediate effect of Suboccipital muscle inhibition technique in subject with short hamstring syndrome and concluded that according to the FFT, SLR and popliteal angle test, the SMI technique modified the elasticity of the hamstring muscle. Moreover, Sung-Hak Cho et $\mathrm{al}^{31}$ also stated that myofascial release of suboccipital muscle could increase the flexibility of the hamstring may be because the superficial back line was relaxed through relaxation of suboccipital muscles, which are the proprioceptor monitors and they are supporting the result of this study.

Thus, to our knowledge there is enough literature available showing immediate effects of neural mobilizations well as myofascial release of suboccipital muscle, on hamstring length compared with other techniques. Both of these techniques showed positive result in decreasing hamstring tightness. But there was no study done to compare the immediate effects of these two techniques.

\section{SUMMARY}

This interventional study was conducted to find the immediate effectiveness of neural mobilisation and myofascial release of suboccipital muscle and concluded that neural mobilisation is more effective in immediately increasing hamstring length when measured by FFT, Sit and reach test.

\section{Acknowledgement: None}

Conflict of Interest: None

\section{Source of Funding: None}

\section{Ethical Approval: Approved}

\section{REFERENCES}

1. Ramos GA, Arliani GG, Astur DC, Pochini $\mathrm{AD}$, Ejnisman B, Cohen $\mathrm{M}$. Reabilitaçãonaslesõesmusculares dos isquiotibiais: revisãodaliteratura. Revista Brasileira de Ortopedia. 2017; 52:11-6.

2. Thomas Myers, Tom Myers, "The 'Fourth' Hamstrings", Massage and Body work, 1998;62-64.

3. Cho SH, Kim SH, Park DJ. The comparison of the immediate effects of application of the suboccipital muscle inhibition and selfmyofascial release techniques in the suboccipital region on short hamstring. J Phys Ther Sci. 2015 Jan;27(1):195-7.

4. Gajdosik RL, Hatcher CK, Whitsell S. Influence of short hamstring muscles on the pelvis and lumbar spine in standing and during the toe-touch test. ClinBiomech (Bristol, Avon). 1992;7(1):38-42

5. Göeken L, Hof A. Instrumental straight-leg raising: Results in patients. Archives of Physical Medicine and Rehabilitation. 1994; 75(4):470-477.

6. Castellote-Caballero Y, Valenza MC, Puentedura EJ et al. Immediate Effects of Neurodynamic Sliding versus Muscle Stretching on Hamstring Flexibility in Subjects with Short Hamstring Syndrome. J Sports Med (Hindawi Publ Corp). 2014; 2014: 127471. doi: 10.1155/2014/127471

7. Weppler $\mathrm{CH}$, Magnusson SP. Increasing muscle extensibility: a matter of increasing length or modifying sensation? Phys Ther. 2010; 90(3):438-49.

8. McHugh MP, Johnson CD, Morrison RH. The role of neural tension in hamstring flexibility. Scand J Med Sci Sports. 2012; 22(2):164-9.

9. Singh AK, Nagaraj S, Palikhe RM, Neupane B. Neurodynamic sliding versus PNF stretching on hamstring flexibility in collegiate students: a comparative study. Int J Phys Educ Sports Health. 2017;1(1):2933. 
HS Krishna et.al. Comparison between immediate effect of neural mobilization and myofascial release of suboccipital muscle on hamstring length in younger adults-an interventional study

10. Singh S, Grover V, Singh S. Effect of neural mobilization and PNF stretching on hamstring flexibility in working women. International journal of health sciences and research. 2015;5(8):361-8.

11. Murphy JC, O'Malley E, Gissane C, Blake C. Incidence of injury in Gaelic football: a 4-year prospective study. Am J Sports Med. 2012; 40(9):2113-20.

12. Safran MR, Garrett WE Jr, Seaber AV, Glisson RR, Ribbeck BM. The role of warmup in muscular injury prevention. Am J Sports Med. 1988; 16(2):123-9.

13. Witvrouw E, Danneels L, Asselman P, D'Have T, Cambier D. Muscle flexibility as a risk factor for developing muscle injuries in male professional soccer players. A prospective study. Am J Sports Med. 2003; 31(1):41-6.

14. Croisier JL. Factors associated with recurrent hamstring injuries. Sports Med. 2004;34(10):681-95

15. Turl SE, George KP. Adverse neural tension: a factor in repetitive hamstring strain? J Orthop Sports Phys Ther. 1998;27(1):16-21

16. Kujala UM, Orava S, Järvinen $M$. Hamstring injuries. Sports medicine. 1997 (6):397-404.

17. Aparicio ÉQ, Quirante LB, Blanco CR, Sendín FA. Immediate effects of the suboccipital muscle inhibition technique in subjects with short hamstring syndrome. J Manipulative PhysiolTher. 2009; 32(4):2629.

18. Puentedura EJ, Huijbregts PA, Celeste S, Edwards D, In A, Landers MR, Fernandezde-Las-Penas C. Immediate effects of quantified hamstring stretching: hold-relax proprioceptive neuromuscular facilitation versus static stretching. Phys Ther Sport. 2011;12(3):122-6.

19. Wallmann HW, Gillis CB, Martinez NJ. The effects of different stretching techniques of the quadriceps muscles on agility performance in female collegiate soccer athletes: a pilot study. N Am J Sports Phys Ther. 2008; 3(1):41-7.

20. Wallmann HW, Mercer JA, McWhorter JW. Surface electromyographic assessment of the effect of static stretching of the gastrocnemius on vertical jump performance. J Strength Cond Res. 2005; 19(3):684-8.
21. Samuel MN, Holcomb WR, Guadagnoli MA, Rubley MD, Wallmann H. Acute effects of static and ballistic stretching on measures of strength and power. J Strength Cond Res. 2008; 22(5):1422-8.

22. Marshall PW, Cashman A, Cheema BS. A randomized controlled trial for the effect of passive stretching on measures of hamstring extensibility, passive stiffness, strength, and stretch tolerance. J Sci Med Sport. 2011;14(6):535-40.

23. Feland JB, Marin HN. Effect of submaximal contraction intensity in contract-relax proprioceptive neuromuscular facilitation stretching. Br J Sports Med. 2004;38(4):E18

24. Etnyre BR, Lee EJ. Chronic and acute flexibility of men and women using three different stretching techniques. Research quarterly for exercise and sport. 1988 1;59 (3):222-8.

25. Gajdosik R, Lusin G. Hamstring muscle tightness. Reliability of an active-kneeextension test. Phys Ther. 1983; 63(7):108590.

26. Ellis RF, Hing WA. Neural mobilization: a systematic review of randomized controlled trials with an analysis of therapeutic efficacy. J Man ManipTher. 2008; 16(1):822

27. Mhatre BS, Singh YL, Tembhekar JY, Mehta A. Which is the better method to improve "perceived hamstrings tightness"Exercises targeting neural tissue mobility or exercises targeting hamstrings muscle extensibility? International journal of osteopathic medicine. 2013 1; 16(3):153-62.

28. Nunes MK, Fontenele Dos Santos G, Martins E Silva DC, Mota de Freitas AC, Henriques IF, Andrade PM, Machado Dde C, Teixeira S, Neves MO, Dias G, SilvaJúnior F, Bastos VH. Acute effects of neural mobilization and infrared on the mechanics of the median nerve. J Phys Ther Sci. 2016; 28(6):1720-3.

29. Park JM, Cha JY, Kim HJ, Yasuyoshi A. Immediate effects of a neurodynamic sciatic nerve sliding technique on hamstring flexibility and postural balance in healthy adults. Physical Therapy Rehabilitation Science. 2014;3(1):38-42.

30. Aparicio ÉQ, Quirante LB, Blanco CR, Sendín FA. Immediate effects of the suboccipital muscle inhibition technique in subjects with short hamstring syndrome. J. 
HS Krishna et.al. Comparison between immediate effect of neural mobilization and myofascial release of suboccipital muscle on hamstring length in younger adults-an interventional study

Manip. Physio. Ther. 2009 May 1;32 (4): 262-9.

31. Cho SH, Kim SH, Park DJ. The comparison of the immediate effects of application of the suboccipital muscle inhibition and selfmyofascial release techniques in the suboccipital region on short hamstring. J Phys Ther Sci. 2015; 27(1):195-7.

32. Aparicio EQ, Quirante LB, Blanco CR, Sendín FA. Immediate effects of the suboccipital muscle inhibition technique in subjects with short hamstring syndrome. J
Manipulative PhysiolTher. 2009; 32(4):2629.

How to cite this article: HS Krishna, Sreejisha PK, Dhote C. Comparison between immediate effect of neural mobilization and myofascial release of suboccipital muscle on hamstring length in younger adults-an interventional study. International Journal of Science \& Healthcare Research. 2021; 6(3): 438-445. DOI: https:// doi.org/10.52403/ijshr.20210771 